Revista Transgressões: ciências criminais em debate, v. 4, n.2, Novembro 2016, Natal/RN

\title{
MПНAEL KOHLHAAS
}

\section{Uma breve análise através da justiça kelseniana}

\section{Matheus Rabello Fernandes Lopes}

Graduando em Direito pela UFRN, interessado em Filosofia do Direito, Filosofia Política e Ética.

E-mail: matheusrflopes@gmail.com

\section{REFERÊNCIA DA OBRA EM ANÁLISE}

KLEIST, Heinrich von. Michael Kohlhaas. Rio de Janeiro: Civilização Brasileira, 2014. 


\section{APRESENTAÇÃO DO AUTOR}

Profundamente influenciado pela obra de Immanuel Kant, mais especificamente sua "Crítica da faculdade do juízo", Bernd Heinrich Wilhelm von Kleist é um dos maiores expoentes da literatura alemã, ao lado de nomes como Johann Goethe, Thomas Mann e Herman Hesse. Nascido em 1777, em Frankfurt an der Oder, na Prússia, Heinrich von Kleist aparece na história como um homem moderno, profundamente envolvido com as radicais mudanças políticas e sociais ocorridas na Alemanha no início do século XIX.

Para Keist, teorias de reforma social e experimentos literários deveriam andar lado a lado. Falar do autor é falar de inquietude de espírito, de sentimento absoluto, do eu nômade e abandonado de si, do sujeito sem unidade. Sua vida inteira foi marcada pela constante busca pela felicidade, busca por projetos de vida e pela recorrente desilusão, traço que também se reflete na sua obra.

Ainda com pouca idade, de família aristocrática e já abalado pela orfandade, ingressa na carreira militar. Desiludindo-se posteriormente, mesmo obtendo diversas promoções de cargo, abandona o militarismo e se volta aos estudos, entre eles a filosofia, a física, a matemática e a ciência política. De modo semelhante, também abandona os estudos ao se deparar cruamente com a relatividade da verdade, momento em que todo o esforço perde o sentido.

Kleist é, antes de tudo, um espírito inquieto. Mudou-se constantemente, passou a vida inteira alternando de cidade em cidade, de círculos sociais em círculos sociais. Sua obra é notadamente marcada por essa peculiaridade: seus protagonistas podem ser vistos como livres da introspecção e profunda ponderação característica do povo alemão; eles são ativos, atuam na realidade, encaram o mundo da forma que lhes é apresentado e trabalham com as cartas à mão, buscando colocar em prática seus ideais.

Noivo de Wilhelmine von Zenge, o escritor queixou-se diversas vezes pela falta de reconhecimento de seu trabalho. Dedicado a buscar a morte na guerra, pretendia se juntar ao exército francês para lutar contra a Inglaterra, mas foi convencido a desistir da empreitada. Em 21 de novembro de 1811, aos 34 anos, conforme carta de poucos dias antes, encontrava-se "tão ferido que eu quase poderia dizer que, quando ponho meu nariz para fora da janela, a luz do dia que brilha sobre ele me dói", certo de que "nada na terra poderia me ajudar", Heinrich von Kleist e sua amiga Henriette Vogel, doente de câncer, põem fim às próprias vidas em Berlim, na margem do lago Wannsee, onde até hoje estão sepultados. 


\section{PESPECTIVA TEÓRICA DA OBRA}

Mesmo sem o devido reconhecimento em vida, Heinrich von Kleist é considerado hoje o escritor da maior tragédia alemã (Pentesileia), da principal comédia na sua língua (A Moringa Quebrada) e de uma das mais grandiosas novelas de seu país (Michael Kohlhaas), à qual nos prenderemos neste breve escrito.

A princípio, é de vital importância destacar que seu trabalho é inclassificável. Navegando entre temas clássicos e posturas românticas, captando traços de Shakespeare, Molière e Sófocles, seu trabalho é completamente experimental e subjetivo. Assim como Shakespeare, utilizou-se por diversos momentos de personagens históricos, caso inclusive de Michael Kohlhaas, baseado no Hans Kohlhasen da vida real, executado em março de 1540.

O contexto de escrita da novela, entre os anos 1805 e 1810, é marcadamente conturbado, época das vitórias de Napoleão contra a Alemanha e de divisão política dos príncipes alemães quanto ao francês. Michael Kohlhaas surge então, neste contexto, como um resgatador do abolido Fehderecht, o direito de tomar satisfações individualmente contra injustiças cometidas, ainda praticado pela nobreza na época da escrita. Esse traço é importante por ser o veículo que dá movimento ao aspecto central do escrito: o embate filosófico entre a liberdade individual e a opressão governamental; entre o povo e a nobreza. O protagonista avança cegamente em busca da justiça, questionando-se quais meios são permitidos para buscá-la e punir os atos reprováveis cometidos por outros, evidentemente movido pela inspiração da interferência efetiva na realidade.

A novela em análise antecipa de forma majestosa e moderna movimentos literários muito posteriores historicamente, como o expressionismo e o existencialismo, e serve de influência direta a Franz Kafka e inúmeros outros escritores, principalmente pela sua tendência ao desapontamento e por desestruturar o sujeito, por carregar consigo a "penúria geral do mundo", conhecendo profundamente a frágil constituição do mundo em si.

\section{BREVE SÍNTESE DA OBRA}


Michael Kohlhaas foi "um dos homens mais honestos e ao mesmo tempo mais terríveis de sua época" (KLEIST, 2014, p. 5). Comerciante de cavalos, homem admirado em sua aldeia e afeto à caridade e à justiça, certa vez se dirigia ao estrangeiro para comercializar alguns de seus cavalos quando, ao passar nas terras do novo fidalgo Wenzel von Tronka, já depois da fronteira, deparou-se com uma cancela impedindo sua passagem. O guarda lhe informara que se tratava de privilégios do novo fidalgo, que agora cobrava pela passagem. Quando estava a passar pela cancela após pagar o que lhe era devido, foi surpreendido pelo alcaide do castelo, que veio ao seu encontro perguntando por um certo salvo-conduto que deveria ter para transitar com cavalos naquelas terras.

Desconhecedor de tal documento e, notadamente, de bom e justo coração, Kohlhaas se desculpa e pede que, devido ao mau tempo, apenas por esta vez deixem-no passar, que providenciaria o requerido documento em Dresden, capital à qual se dirigia. Replicando que seria impossível e que o decreto era novo e indispensável, o alcaide leva o comerciante ao fidalgo von Tronka, momento em que, após examinar os cavalos, movido pelas influências extorsivas do alcaide, o fidalgo demanda que deixe dois de seus animais como garantia de que voltará com o documento.

Ao chegar a Dresden, porém, descobre que tal documento nunca existiu e, passadas algumas semanas nas quais conseguiu vender os animais que levara, volta à fortaleza para encontrar seus dois lustrosos cavalos completamente destruídos pelo trabalho ao qual foram submetidos e seu servo espancado e expulso.

É neste momento que se inicia a empreitada do protagonista. Profundamente tomado pelo seu forte sentimento de justiça, sabedor de que seu caso não foi o primeiro nem seria o último, busca instância após instância dos tribunais e dos príncipes para solucionar seu caso, encontrando sempre à frente alguma manobra institucional e de influência política do fidalgo para impossibilitar o feito. A própria valorização da justiça, que tanto o tornara admirável por todos que o conheciam, o levaria à destruição.

Como um anjo vingador, Kohlhaas busca a todo custo fazer justiça por si. Tenta de todos os modos, reúne grupos de apoiadores por onde passa, incendeia castelos, vilas e cidades, apoiando-se no peso da espada, na ajuda divina e até no misticismo de uma cigana. Tudo para descobrir que desde o princípio, quanto mais buscava pela justiça, mais se aproximava do alçapão de sua própria destruição.

Condenado à morte, com a esposa morta e sem mais terra ou trabalho a retornar, Kohlhaas atinge por fim a satisfação de sua demanda, ao preço alto de destruir tudo aquilo que ele já foi e tudo que conhecia. 


\section{PRINCIPAIS TESES DESENVOLVIDAS NA OBRA E REFLEXÕES CRÍTICAS}

Levantado por Marcelo Backes no posfácio da obra, "Michael Kohlhaas é uma porta aberta à interpretação, ampla e evasiva. As contradições são extremas, e todo mundo lê no herói o que quer, insere no texto a ideia que melhor lhe aprouver" (KLEIST, 2014, p. 157). De fato, uma análise da novela nos revela diversas possibilidades de abordagem às tantas questões que são inseridas a todo momento, como a justiça com as próprias mãos, a problematização em torno do contrato social, as profundas raízes da influência política dentro dos órgãos de resolução de demandas, as eternas buscas burocráticas sob a decepção e perplexidade kafkiana.

Dentre tantos possíveis pontos, optamos por focar no binômio central da composição da obra: o choque entre direito e justiça. Pode-se dizer que a sede com a qual Kohlhaas buscou concretizar sua demanda é um indicativo de que as leis e instituições estavam erradas em sua postura? Tomadas as devidas proporções, como ponderar entre o senso de justiça pessoal e o institucionalizado?

Perante este ponto focal, buscamos no jurista e filósofo austríaco Hans Kelsen o norte para a investigação filosófica à qual nos propomos. Identificando pontos de intersecção da problemática para, por fim, sugerir uma possibilidade de abordagem da novela kleistiana, sem, de nenhuma forma, fechar o horizonte a outras visões e perspectivas.

Desta forma, em um primeiro momento, identificaremos as principais teses referentes à justiça desenvolvidas por Kleist para, em seguida, nos prendermos à análise pela ótica da obra kelseniana.

Inicialmente, uma passagem central para compreendermos a visão de justiça e de direito em torno do texto é o momento em que Kohlhaas decide vender sua terra. Sua esposa, incrédula, pergunta por seus motivos, e ele responde:

[Vendo a casa] porque não gosto de ficar em um território, querida Lisbeth, no qual não querem me proteger em meus direitos. Melhor ser um cachorro, se devo levar chutes por aí, do que ser um ser humano! [...]

De onde sabes, disse ela furiosamente, que não vão te proteger em teus direitos? Se te aproximares do soberano com humildade conforme deve ser, 
apresentando tua petição, de onde sabes que ela será jogada de lado, ou que se negarão a te ouvir?

Pois bem, respondeu Kohlhaas, se meu temor é infundado em relação a isso, também minha casa não estará vendida. O soberano, ele mesmo, é justo, eu sei. (KLEIST, 2014, p. 31)

Torna-se evidente o fundado respeito do personagem à lei e a inserção que ele faz da justiça junto à figura do soberano. Para Kohlhaas, o direito deve ser justo, e se não o for, não deve a ele se submeter de nenhuma forma. Melhor seria ser um cachorro, um vagante.

Ao ver posteriormente ser ordenado pelo soberano que ele pegue seus cavalos e nada mais faça quanto a isso, ou seja, que não busque qualquer outro ressarcimento pelas condições dos cavalos e de seu servo, concretiza-se no texto o afastamento definitivo entre direito e justiça para Kohlhaas. É a partir deste ponto, da ideia de que pelos meios tradicionais de obtenção de justiça sua demanda não seria atendida, que se inicia a jornada do protagonista em busca de fazer com que seu senso de justiça particular se aplique, da forma que se fizer necessária.

Um meio merecedor de atenção do qual o personagem se vale para vigorar sua perspectiva é o "Manifesto Kohlhaasiano", que ordenava a todo o povo que entregasse a ele o fugitivo fidalgo von Tronka, sob pena de perder a vida e ver todos os seus bens queimados, visto tratar-se de uma justa guerra particular. Por intermédio do manifesto, Michael Kohlhaas leva sua justiça particular ao nível de lei.

Observando-se o manifesto, resta claro o uso da força e da ameaça para atingir seus objetivos. Utilizando-se da força, todavia, não se pode falar em direito, mas sim em escravidão ou arbitrariedade.

Por um meio de observação, a visão de justiça individual que é forçada para os cidadãos não é de fato direito. O que para o protagonista não era nada além de justo, tratava-se antes de um ato arbitrário de força e opressão, na visão de Jean-Jacques Rousseau:

O mais forte nunca será forte o bastante para ser sempre o amo se não transformar sua força em direito e a obediência em dever. [...] A força é uma potência física, não vejo que moralidade pode resultar dos seus efeitos. Ceder à força é um ato de necessidade, não de vontade; é no máximo um ato de prudência. [...] Já que nenhum homem tem uma autoridade natural sobre seu semelhante e já que a força não produz nenhum direito, restam pois as convenções como base de toda autoridade legítima entre os homens. (ROUSSEAU, 2011, p. 58-59). 
Não existe a possibilidade de derivar, a princípio, moralidade do uso da força. Portanto, para Rousseau, a única forma de legitimar a arbitrariedade seria se todas as gerações futuras passassem a aceitar como convenção aquele governo; mas, nesse caso, não trataria mais de um governo arbitrário (ROUSSEAU, 2011, p. 60).

Em Rousseau, o estado social, no qual tudo está sob a autoridade das leis, devese reger pela vontade geral (volonté générale) acima de tudo, vontade esta que é encontrada partindo da pergunta "em relação a este tópico, o que é o melhor para a comunidade?", não o melhor para si ou para um grupo.

Hans Kelsen em muito compactua com a ótica rousseauniana, como poderemos constatar. Para Kelsen, é basilar a ideia de que "a norma de justiça é uma norma moral; e, assim, também sob este aspecto o conceito da justiça se enquadra no conceito da moral" (KELSEN, 1993, p. 4).

"Justiça" em Kelsen significa a qualidade de uma conduta humana, valorada através do juízo de justo ou injusto daquele que observa a conduta. Uma ação é, portanto, apreciada perante uma norma de justiça, norma moral que é diferente de uma norma positiva, e só daí constatamos se é uma ação relativamente justa. Em suma, frente à visão que Kohlhaas tem de que o direito deve ser justo e que se afastar da justiça o tornaria inválido, que seria melhor ser um cachorro a viver sob tal regra, Kelsen (1993, p. 7) conclui:

[...] Quando falamos de um direito positivo justo ou injusto, quando afirmamos a justiça ou injustiça como qualidade de normas válidas do direito positivo, quando, como se diz, julgamos as normas do direito positivo segundo uma norma de justiça, as valoramos como justas ou injustas tomando por padrão de medida uma norma de justiça e presumindo ao mesmo tempo, contudo, que a validade dessas normas de direito positivo não depende da relação em que se encontrem com a norma de justiça. (KELSEN, 1993, p. 7).

Ressaltem-se dois pontos: primeiro, julga-se uma norma de direito positivo segundo "uma" norma de justiça, em outras palavras, uma entre muitas; segundo, a validade de uma norma de direito positivo não depende de sua relação com a norma de justiça escolhida pelo observador. Deve-se tomar toda a cautela devida ao transitar entre este terreno da teoria kelseniana, visto tratar-se de um dos campos que mais geram polêmica e discórdia. Para caminhar por esta floresta teórica, portanto, iremos com toda a calma que a matéria requer.

Quanto ao primeiro ponto, o autor é categórico ao afirmar que "a unanimidade sobre um juízo de valor existente entre muitos indivíduos não é absolutamente prova de 
que esse juízo seja correto" (KELSEN, 1998a, p. 8). A noção de justiça não é uma noção absoluta, na visão positivista: não é possível conhecer a justiça absoluta, então todos os referenciais que tomamos são completamente relativos e particulares, mesmo que aceitos por muitos. Em oposição, o direito natural crê que possa ser identificada "a" norma de justiça, aplicável e válida enquanto norma. Para esta corrente, direito válido é direito justo: uma regulamentação injusta da conduta humana não seria válida por não ser direito.

Desta forma, utilizando-nos do positivismo kelseniano, a noção de justiça de Kohlhaas perante o que foi feito pelo fidalgo von Tronka também pode ser encarada como relativa, de modo que não pode se confundir de nenhuma forma com a norma positiva, nem ser usada como parâmetro para invalidá-la. Estaria errada, então, a sua noção de que a justiça e o direito devem andar lado a lado a todo o momento? Normas positivas, mesmo que injustas, são válidas?

As perguntas nos levam ao segundo ponto, o da relação entre a validade de uma norma positiva e uma norma de justiça. Da leitura da obra kelseniana, depreende-se que a validade de uma norma jurídica independe de sua justiça, como frisa o autor:

\footnotetext{
Abstrair da validade de toda e qualquer norma de justiça, tanto da validade daquela que está em contradição com uma norma jurídica positiva como daquela que está em harmonia com uma norma jurídica positiva, ou seja, admitir que a validade de uma norma do direito positivo é independente da validade de uma norma de justiça - o que significa que as duas normas não são consideradas como simultaneamente válidas - é justamente o princípio do positivismo jurídico. (KELSEN, 1993, p. 11)
}

Kelsen envida grandes esforços para investigar "por que a lei deve ser obedecida?", e inclusive se confronta com a ideia naturalista de que uma lei deve ser obedecida por estar em conformidade com princípios da moral, sustentada pelo protagonista da obra kleistiana.

Para o jurista, tal teoria falha ao submeter o direito positivo ao direito natural, ou seja, à ideia de que investigando a natureza podemos encontrar o que é justo e o que é correto. Uma norma é uma expressão de vontade, e não é possível extrair uma vontade da natureza (KELSEN, 1998a, p. 252). Todavia, tais afirmações não significam de nenhuma forma que as leis não possam de nenhuma forma ser justas nos olhos do observador. Diferencial parâmetro entre a doutrina do direito natural e a do direito positivo no quesito “justiça” é o exato momento no qual a valoração deve ser feita.

Enquanto no direito natural uma norma pode ser invalidada pelo seu observador ao perceber que se afasta do princípio natural ou divino de justiça, o direito positivista 
kelseniano diria que devemos obedecer a uma norma criada por uma autoridade política porque, em última análise, estamos obedecendo à constituição, a uma norma hipotética fundamental, não emitida por uma autoridade política, que lhes confere validade (KELSEN, 1998a, p. 256-257).

Portanto, mesmo que injusta aos olhos do observador, frise-se, a norma jurídica continua perfeitamente válida, pois sua validade independe de sua justiça, como afirmado. Está sustentada antes na própria estrutura hierárquica do direito, e acima de tudo na norma hipotética fundamental.

A ciência do direito não pode responder à questão de se uma norma é ou não justa porque, cientificamente, essa pergunta não possui resposta alguma (KELSEN, 1998a, p. 262). Entretanto, os atos das autoridades políticas criadoras das normas podem - e devem, arriscaria dizer - ser revestidos de noções de justiça. As normas de justiça dizem como deve ser elaborado o conteúdo do direito, como devem ser reguladas as condutas humanas.

Este é o momento no qual o direito entra em consonância com a justiça: no seu momento de criação, seja pelo legislador ou pelo juiz, autoridades legitimadas pelo próprio direito para exercer interpretação autêntica (KELSEN, 1998b, p. 394-395).

Sob o lume kelseniano, a obra de Heinrich von Kleist desperta inúmeras conclusões e campos de discussão acadêmica e social. Percebe-se que Michael Kohlhaas não está de todo errado ao confrontar um acontecimento (o desrespeito do fidalgo Wenzel von Tronka) com o que cria ser a norma soberana naquele momento. Leve-se em consideração que o direito baseado na autoridade exclusiva do soberano tem como característica a fácil mutabilidade e possibilidade de atender a demandas de formas diferentes.

Em Kelsen, caso se tratasse de um Estado com direito positivado estável, caberia a Kohlhaas fazer valer seu direito por meios políticos. $\mathrm{O}$ afeto kelseniano pelo meio político como modo de alterar as normas sociais é uma característica forte de sua teoria. O comerciante de cavalos estaria apto a buscar as autoridades legítimas, a exemplo do corpo legislativo, para criar normas que satisfizessem seu desejo, inserindo sua visão de justiça no direito positivo.

Do mesmo modo que Kelsen, a teoria de Rousseau, como visto, também recriminaria a solução forçosa adotada, visto tratar-se de um ato que vai de encontro à volonté générale e à base de igualdade e liberdade necessárias à formação estatal. É por estas e tantas outras provocações existentes na obra que Marcelo Backes aponta, no 
posfácio, que "diante de uma obra como Michael Kohlhaas, não são poucos os que pensam, impotentes diante da própria arte, que talvez tudo já tenha sido dito" (KLEIST, 2014, p. 144).

\section{REFERÊNCIAS}

KELSEN, Hans. O problema da justiça. 1. ed. São Paulo: Martins Fontes, 1993.

O que é justiça?: a justiça, o direito e a política no espelho da ciência. 2. ed. São Paulo: Martins Fontes, 1998a.

Teoria pura do direito. 6. ed. São Paulo: Martins Fontes, 1998b.

KLEIST, Heinrich von. Michael Kohlhaas. Rio de Janeiro: Civilização Brasileira, 2014.

ROUSSEAU, Jean-Jacques. Do contrato social ou princípios do direito político. 1. ed. São Paulo: Penguin Classics Companhia das Letras, 2011. 